\title{
Prevalence and Morphometric Characteristics of the Mandibular Incisive Canal through Panoramic Radiographs in a Chilean Population
}

\author{
Prevalencia y Características Morfométricas del Canal Incisivo Mandibular \\ a través de Radiografías Panorámicas en Población Chilena
}

Ramón Fuentes $^{1,2}$; Alain Arias ${ }^{1,2,3}$; Cristina Bucchi ${ }^{1,2}$; Diego Saraviaa ${ }^{2,3,4}$ \& Fernando Dias ${ }^{1,2}$

FUENTES, R.; ARIAS, A.; BUCCHI, C.; SARAVIA, D. \& DIAS, F. Prevalence and morphometric characteristics of the mandibular incisive canal through panoramic radiographs in a Chilean population. Int. J. Morphol., 35(3):931-937, 2017.

SUMMARY: The mandibular incisive canal (MIC) is a continuation of the mandibular canal, anterior to the mental foramen, containing the neurovascular bundle of the teeth in anterior mandibular segment. The aim of this study was to calculate the prevalence and analyze the morphometric parameters of MIC in a Chilean population through digital panoramic radiographs. A cross-sectional study was performed using 500 digital panoramic radiographies of adult individuals. The prevalence of MIC was set in different sexes, age groups and proximity to teeth; in addition to the morphometric parameters of length, width (diameter) and distances of MIC to dental element and the mandibular base. General MIC prevalence was $53 \%$ (265 cases), $49.9 \%$ in women and $57 \%$ in men. In the age groups, prevalence was higher in men, MIC was predominantly associated to first premolars (98.2 \% - women; $90 \%$ - men), however a relevant number ( $42.6 \%$ women; $55.1 \%$ - men) was close to the canines. The MIC length ranged from 2.6 to $18 \mathrm{~mm}$ (median - 5 to $8 \mathrm{~mm}$ ), the width of 0.8 to $5.4 \mathrm{~mm}$ (median - 2 to $3 \mathrm{~mm}$ ), the distance to other elements from 0.6 to $12,5 \mathrm{~mm}$ (medians -5 to $7 \mathrm{~mm}$ ) and the margin of the mandible from 4.1 to $16.7 \mathrm{~mm}$ (median -8 to $10 \mathrm{~mm}$ ). The length decreases in older age groups regardless of sex. Width and distance the mandibular base was larger in men compared to women.

KEY WORDS: Mandibular Incisive Canal; Prevalence; Morphometry; Chilean population.

\section{INTRODUCTION}

The mandibular incisive canal (MIC) is an anterior extension of the mandibular canal from the mental foramen, which contains a neurovascular bundle (Mardinger et al., 2000; Romanos et al., 2012). The precise anatomy and content of the MIC are still a matter of discussion (Beltrán et al., 2011). Since its anatomical description has been inconsistent, some researchers report this structure as a discrete canal, others consider the canal as a nervous plexus, and some studies do not mention its existence at all ( $\mathrm{Vu}$ et al., 2015). Despite these discrepancies, there are numerous reports that confirm the presence of MIC in the region located between both mental foramina, through anatomical dissection (Uchida et al., 2007; Vu et al.; Xu et al., 2015) and cone beam tomography imaging. (Jacobs et al., 2002;
Kajan \& Salari, 2012; Orhan et al., 2014). The anatomical characteristics of this and other structures could be associated with race (Xu et al.).

The presence of MIC and its morphological characteristics should be considered in clinical procedures such as dental implant planning and placement, chin bone collection, orthognathic surgery and periapical surgery (Beltrán et al.). Placement of implants in the anterior mandibular region with perforation of the MIC can generate edema of the epineurium, which could expand into the main mental branch and cause neurosensitive disturbances (Marginger et al.) such as paresthesia and failure in osseointegration of dental implants (Orhan et al.). These

\footnotetext{
${ }^{1}$ Department of Integral Dentistry, Dental School, Universidad de La Frontera, Temuco, Chile.

${ }^{2}$ Research Centre in Dental Sciences (CICO), Dental School, Universidad de La Frontera, Temuco, Chile.

${ }^{3}$ Master's Program in Dentistry, Dental School, Universidad de La Frontera, Temuco, Chile.

${ }^{4}$ Universidad Adventista de Chile, Chillán, Chile.
} 
alterations, along with the hemorrhage, are common complications of the procedures performed in this area (Kajan \& Salari). These characteristics reveal the need for the clinician to identify and consider MIC and its anatomical variations while planning treatments that involve this area.

In order to prevent the occurrence of these complications, a careful radiographic evaluation is necessary (Orhan et al.). The Panoramic radiography is widely used in clinic with a variety of purposes (Jacobs et al., 2004; Romanos et al.; Raitz et al., 2014), such as the identification of important anatomical and morphometric features. The knowledge of anatomy in this area is poorly documented (Raitz et al.) and even more so identification of the MIC in this type of radiographs (Jacobs et al., 2004). It is important to consider that in many surgeries for implants and implant-supported prostheses in the mandible, only panoramic radiographies are used as a diagnostic method, due to the safety that the anterior region provides for these types of procedures (Raitz et al.).

The objective of this study was to analyze the prevalence of MIC through digital panoramic radiographs of a sample of Chilean patients. In addition, to obtain and discuss morphometric parameters of this channel associated to adjacent structures between different sexes and age groups.

\section{MATERIAL AND METHOD}

A cross-sectional descriptive study was performed, 500 digital panoramic radiographs (ratio 1:1) taken in March of 2015 at the Dental Assisting Teaching Clinic, Dental School, Universidad de La Frontera (Temuco, Chile) were analyzed. Radiographs were taken under standard technique with PAX-400C orthopantomograph (VATECH, Korea, 2010). This study has the approval of the Ethical Scientific Committee (CEC) of the Universidad de La Frontera through folio $n^{\circ} 015 / 2014$.

All radiographs analyzed in this study were obtained from patients of known age and sex. The following exclusion criteria were applied: Radiographs with distortion or contrast alteration, radiographs of patients younger than 18 years old, radiographies showing presence of pathology, included teeth, presence of titanium plates in the mandibular area and radiographs with evidence of orthognathic surgery.

All panoramic digital radiographs were projected onto a 29-inch LED monitor (LG, model 29UM67) with a resolution of $2560 \times 1080$ pixels and analyzed by a single examiner. The intraobserver reliability was evaluated by performing duplicate examinations of $10 \%$ of the radiographs studied. There was a one-week interval between the first and second measurements. Both sides of the jaw were analyzed independently.

The radiographs were initially classified between sexes and three different age groups (18-30, 31-50, 50-100 years of age). After this classification, all the radiographs were analyzed in order to find which of them had at least one visible mandibular incisive canal. All MIC found in the radiographs were delimited in red (Fig. 1).

Morphometric Analysis. For the morphometric analysis of the incisor canal, software "ImageJ" (1.47s, free, NIH, USA) was used. The software is frequently used in histological morphometric studies; it also has the advantage of being free and easy to manipulate, thereby reducing cost and facilitating the reproducibility of the measurement protocol carried out in the present study.

The standardized digital archives of the panoramic radiographs had their scale adjusted in the software, by known measures that provided a reliable and accurate analysis. The simple and composite linear measurement software was used, measuring structures with varied angulations.

The following were measured:

1. Length of incisor canal (Fig. 1B - yellow line);

2. Incisive canal width, measured in 3 distinct points (proximal, intermediate and distal, Fig, 1C - yellow line);

3. Distance from the base of the incisor canal to the base of the mandible (Fig. 1D - yellow line);

4. Minimum distance of the roots of the teeth present on the incisor canal to the canal ceiling (Fig. 1E-yellow line).

Statistical analysis. Morphometric data were obtained and compared between sexes and different age groups. The statistical analysis was performed with using SigmaPlot 12.0 software (Systat software Inc, San Jose, CA, USA). The Shapiro-Wilk test was selected to assess data normality. For data with normal distributions, the one-way ANOVA $(\mathrm{p}=0.05)$ with the Holm-Sidak post hoc test (Holm, 1979) was performed, and the data presented as the mean \pm SD. For no normal distribution data, the Kruskal-Wallis test was performed, along with a Dunn's post hoc test, in which case the data is presented as the median, low (25\%) and high (75\%). 


\section{RESULTS}

Mandibular Incisive Canal Prevalence. 500 radiographs of adult patients were analyzed, $265(53 \%)$ reveals at least one incisor canal that could be identified and evaluated. The general comparison between sexes (Graph 1) showed a higher prevalence in men (57\%) compared to women $(49.9 \%)$.

The comparison between the radiographs of male and female patients of different age groups revealed that the prevalence was higher in men in all age groups. In women, there is a continuous reduction in prevalence in older age; in males the intermediate age group (31-50 years) presented the highest prevalence, however with the same trend of reduction at older ages.

The analysis of MIC visible localization on the panoramic radiographs, in association with the teeth that are present above its path, revealed that the first lower premolar presents in $98.19 \%$ between women and $90 \%$ in men above the MIC path. The second element that was most frequent above the MIC path was the lower canine with $42.59 \%$ in women and $55.1 \%$ in men.

Mandibular incisive canal morphometrics. The length of the mandibular incisive canal presented a median of 5 to 8 $\mathrm{mm}$ in the different age groups of both sexes. No significant differences between the sexes were observed, such as when comparing data from the same age groups of the different sexes. However, differences in ages of the same sex were observed, W18-30 (6.9; 5,9; 8.4 mm) had significantly larger incisor canal length compared to W51-100 $(5.7 ; 4.9 ; 6.7 \mathrm{~mm})$, the same pattern was observed in males M31-50 (7.1; 6.1; 8.1 $\mathrm{mm}$ ) that presented the incisor canal with significantly greater length compared to M51-100 (5.6; 5; $6.3 \mathrm{~mm})$.


Fig. 1 - Morphometric analysis of the MIC - A. MIC delimitation in red. B. Measuring the length of the MIC using the ImageJ software. C. Measurement of the width (diameter) of the MIC at the most proximal point, this procedure was also performed in the middle and distal regions of the MIC. D. Measurement of the distance from the MIC to the edge of the mandible in the middle region, this procedure was repeated in the proximal and distal regions. E. Measuring the shortest distance between the MIC and the dental elements, this procedure was repeated as many times as necessary to relate all the teeth that were on the MIC trajectory. 


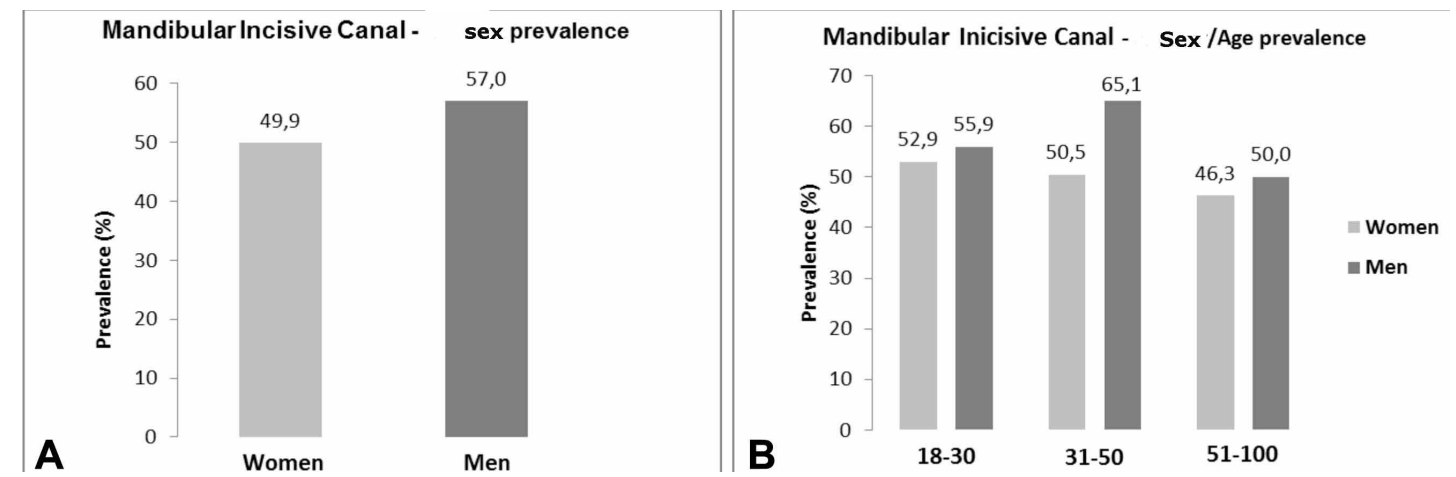

Fig. 2 - A. General prevalence of MIC by sex. B - Prevalence of MIC by sex and age. C - Association of dental elements located above the MIC.

Mandibular Incisive Canal - Lenght

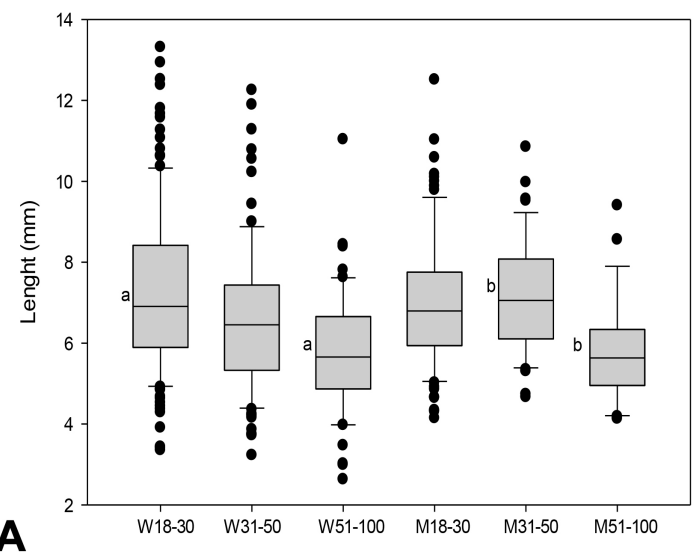

Dental Distance to MIC

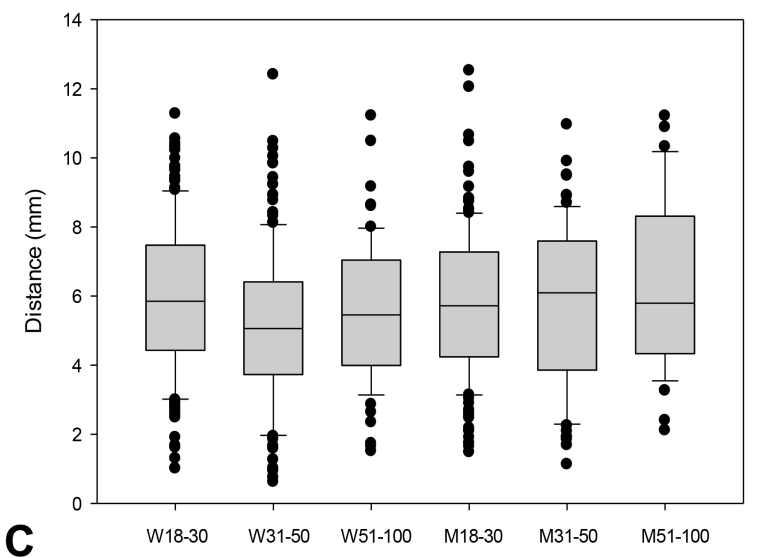

Mandibular Incisive canal - Width (Diameter)

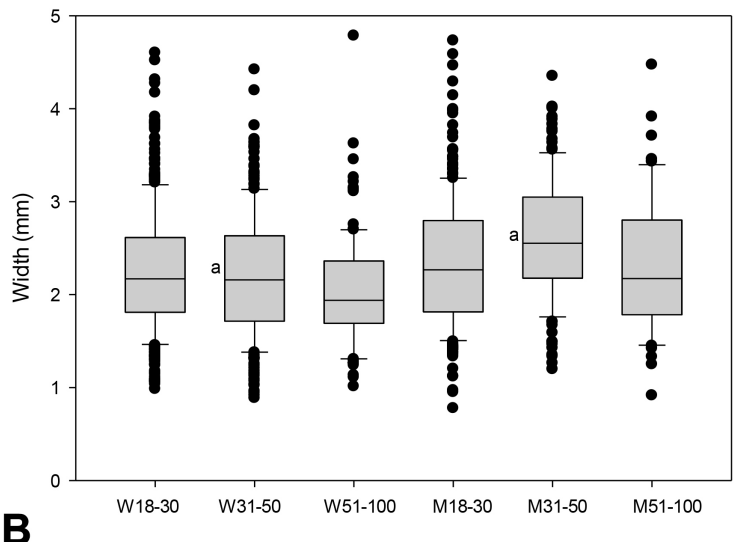

Mandible lower border distance to MIC

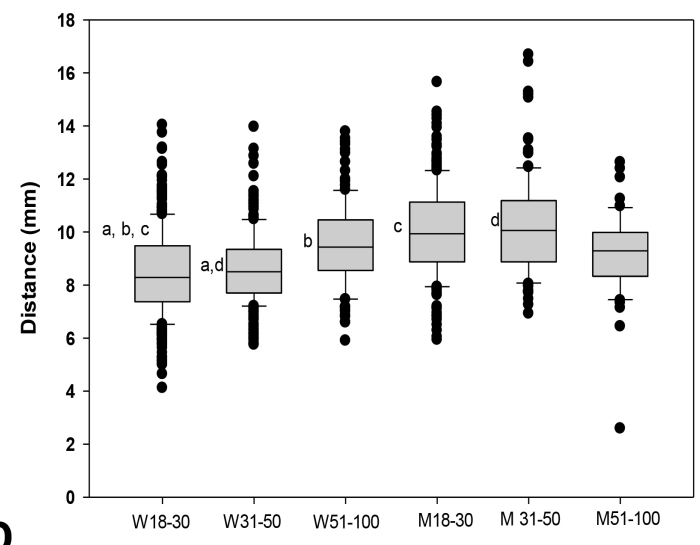

Fig. 3 - A. Length of MIC, comparison between sexes and ages. The letter 'a' marks the significant difference between groups W18-30 and W51-100 and letter 'b' between groups M31-50 and M51-100. In both cases p> 0.05. B -Width of MIC, comparison between sexes and age. Letter 'a' marks a significant differences between W31-50 and M31-50 ( $p<0.05$ ). C - Distance from MIC to teeth, comparison between sexes and age groups. There were no significant differences between groups. D - Distance of the MIC at the base of the mandible, comparison between sexes and age groups. The letter 'a' shows significant difference between the W18-30 and W31-50; the letter 'b' between W18-30 and W51-100; the letter 'c' shows difference between W18-30 and M18-30; and the letter ' $\mathrm{d}$ ' is the difference between W31-50 and M31-50 in all cases p>0.05. 
The width of the incisor canal presented a median between 2 and $3 \mathrm{~mm}$ in all age groups of both sexes. There was no significant difference between the age groups in the different sexes. However, a significantly wider canal was observed in men aged $31-50$ years $(2.55 ; 2.18 ; 3.05 \mathrm{~mm})$ compared to women $(2.16 ; 1.72 ; 2.63 \mathrm{~mm})$ in the same age group.

The distance from the root apex to the mandibular incisor canal presented values of the median ranging from 5 to $7 \mathrm{~mm}$, however, values of approximately $1 \mathrm{~mm}$ and 12 $\mathrm{mm}$ were also observed. No differences were found between sexes and between age groups.

Regarding the distance from the canal to the base of the mandible, the median values were between 8 and $10 \mathrm{~mm}$ with a wide variation, from approximately $2 \mathrm{~mm}$ to greater than $16 \mathrm{~mm}$. Significant differences were present in women of different ages W18-30 $(8.28 ; 7.37 ; 9.48 \mathrm{~mm})$ and W3150 (8.5; 7.7; $9.34 \mathrm{~mm}), \mathrm{W} 18-30$ and W51-100 (9.43; 8.55; $10.46 \mathrm{~mm}$ ). In addition to differences between sexes of the same age range, M18-30 $(9.93 ; 8.87 ; 11.13 \mathrm{~mm})$ presented significantly higher values compared to women of the same range, such as M31-50 (10.06; 8.88; $11.18 \mathrm{~mm})$.

\section{DISCUSSION}

The studies analyzing the importance and prevalence of MIC are numerous and still current and performed in several countries, such as Brazil (Pires et al., 2012; Raitz et al.; PereiraMaciel et al., 2015; Ramesh et al., 2015), Turkey (Sahman et al., 2014), Byelorussia (Kabak et al., 2016), Greece (Romanos et al.; Apostolakis \& Brown, 2016) and China (Kong et al., 2016). The methods of analysis used were panoramic radiography (PAN) (Jacobs et al., 2004; Kong et al.; Sahman et al.; de Brito et al., 2016; Pires et al.; Raitz et al.), and the use of cone beam computerized tomography (CBCT) (Pires $e t$ al.; Raitz et al.; Pereira-Maciel et al.; Sahman et al.; Kabak et $a l$; Kong et al.). However, there is still a high incongruity between the data of these studies, so the prevalence in PAN presented values of $1 \%, 5.5 \% 11 \%, 38.6 \%$ and $51.2 \%$ and in CBCT of $24.4 \%, 71.7 \%, 83 \%, 92 \%, 93 \%$, and $94.4 \%$ to $100 \%$. Notably, the data from the studies show that CBCT analyses were more efficient in both identification and evaluation of MIC (Raitz et al.; Pires et al.).

The radiographs analyzed in the present study revealed a prevalence of MIC in at least one mandibular side of $53 \%$. In the comparisons performed, we observed a higher prevalence in men than in women, and the same reduction pattern associated with higher age groups.
The difference between men and women may be related to the different bone structure between the sexes. The same reduction characteristic is observed with age in both sexes, which may be due to a reduction in the quantity and quality of bone tissue with aging, but no differences were observed between the sexes in any age group. It is noteworthy that in women of the greater age group they could present a lower significant prevalence in comparison to the men, due to the greater propensity to osteoporosis.

Panoramic radiography is often used in dental practices because it provides analysis of anatomical structures in the maxillofacial region (Pires et al.; Romanos et al.; Jacobs et al., 2004). A 3D examination and crosssectional analysis are not routinely recommended (Romanos et al.). Computed tomography (CT) has been the gold standard for many years, as the information provided is threedimensional and generally very accurate. However, CT examinations are expensive and deliver a relatively high radiation dose to the patient (Monsour \& Dudhia, 2008).

The present study reports MIC data from a sample of Chilean population, and although the prevalence of this structure is still a point of debate, especially when using panoramic radiography, our data were similar to those reported by Sahman et al., who reported a prevalence of $51.2 \%$ and even though a difference between the prevalence in individuals of different genera was observed, no significant differences were reported as concluded by Raitz et al.

A previous study of our research group with conventional panoramic radiographs revealed a MIC prevalence of $34.7 \%$ among women and $37.5 \%$ among men, with a tendency to reduce its detection in advancing age (Fuentes et al., 2015). Using digital radiographs, it was possible to observe an increase in the prevalence of MIC in both sexes, in addition to not detecting this trend of reduction associated with age, it may be due to the fact that the better quality of the images obtained by the digital method.

The length of the MIC presented values of 2.6 to 18 $\mathrm{mm}$ with medians among sexes and age groups of 5 and 8 $\mathrm{mm}$. No differences between sexes were noted, only the length detected on the radiographs was lower in the older age group in both men and women. This fact corroborates previous observations of the prevalence, thus the MIC besides presenting lower prevalence in older patients, also present generally a reduction of its length, independent of sex. In this case greater predisposition for osteoporosis in women did not reveal differences in relation to this data.

The values of MIC length previously reported in the literature present varied and discordant mean values: $7 \mathrm{~mm}$ 
(Pires et al.), $8.9 \mathrm{~mm}$ (Apostolakis \& Brown), $10.2 \mathrm{~mm}$ (Ramesh et al.) and $17.8 \mathrm{~mm}$ (Kong et al.) using CBCT; and with PAN method, a value of $10.7 \pm 5 \mathrm{~mm}$ was reported (Romanos et al.), the values of our medians were below these values, confirming the observation by de Brito et al., which reports an underestimation of approximately $2 \mathrm{~mm}$ in the use of PAN.

The range of variation was reported from 0 to 24.6 $\mathrm{mm}$ (Apostolakis \& Brown) and 0 to $19 \mathrm{~mm}$ (de Brito et al.), both studies using CBCT. Our results presented values that were within this range variation, however again underestimated in comparison to the results of the CBCT.

The width (diameter) of the MIC had a mean of 2.3 $\pm 0.7 \mathrm{~mm}$ and the median between 2 and $3 \mathrm{~mm}$ ranging from 0.8 to $5.4 \mathrm{~mm}$, did not reveal a significant variation between the different age groups of the same sex. Significant difference was noted between men and women of 31-50 years, which was not repeated in other age groups.

Previous studies again presented variable data for this parameter showing means of $1.91 \pm 0.45 \mathrm{~mm}$ (Sahman et al.); $2.6 \mathrm{~mm}$ (Ramesh et al.); 0.8 to 2.9 (Mardinger et al.) and up to $4.6 \mathrm{~mm}$ (Pires et al.) using CBCT, a PAN study revealed a mean MIC diameter of $1.5 \pm 0.6 \mathrm{~mm}$ (Romanos et $a l$.) and in cadavers a diameter of $1.8 \pm 0.5 \mathrm{~mm}$ were reported (Mraiwa et al., 2003). Our results are closer to values reported by the CBCT studies, especially those by Pires et al., that presented values greater than $4 \mathrm{~mm}$.

The distance from the MIC to the dental elements presented an average of $5.7 \pm 2.2 \mathrm{~mm}$, with medians between 5 and $7 \mathrm{~mm}$ and values from 0.6 to $12.5 \mathrm{~mm}$. This morphometric parameter presented wide variation, however with no differences and a defined pattern between sex and age groups.

Data from previous studies using CBCT showed values of $5.3 \mathrm{~mm}$ (Pires et al.); 6.9 and $7.3 \mathrm{~mm}$ (Apostolakis \& Brown); $10.25 \pm 2.27 \mathrm{~mm}$ (Pereira-Maciel et al.) and 9.1 $\mathrm{mm}$ (Ramesh et al.) from the MIC distance to the dental elements, and even though our results are within the range of values presented, our mean values were again underestimated in comparison with most of these studies, which did not reveal a concrete agreement due to the high variability of these values.

The distance from the incisor canal to the lower margin of the mandible had a mean of $9.1 \pm 1.8 \mathrm{~mm}$, with values varying from 4.1 to $16.7 \mathrm{~mm}$ and with medians of 8 and 10 $\mathrm{mm}$. This parameter presented a gradual increase in women according to age group, which may be due to dental loss and the change in the position of this canal in the upper direction.
Among men, no difference was observed between the age groups evaluated; however, in comparison with the women, it was observed in the ranges of 18-30 and 31-50 increased values of this parameter. This result corroborates the anterior result of incisor canal width, due to the larger dimensions in men compared to women.

Previous studies using CBCT revealed very different mean values for this parameter of $10.2 \pm 2.4 \mathrm{~mm}$ (Pires et al.); $4.4 \mathrm{~mm}$ and $4.8 \mathrm{~mm}$ (Apostolakis \& Brown); $7.06 \pm$ $2.95 \mathrm{~mm}$. (Pereira-Maciel et al.) and 9,425 mm (Ramesh et al.). A study with PAN presented a value of $16.06 \pm 2.8 \mathrm{~mm}$ (Romanos et al.) and in analysis with cadavers of $9.7 \pm 1.8$ $\mathrm{mm}$ (Mraiwa et al.). Our results were in a range of variation in this parameter, as reported in the literature with different methods used, and the mean was similar to that of Ramesh et al., who used CBCT and Mraiwa et al., with cadaveric dissection.

Morphometric analysis showed that data such as the length, width and distances of the MIC to the dental elements and the lower limit of the mandible are frequently evaluated parameters, due to the fact that this knowledge is clinically interesting to perform treatments in the mandibular intermental area. However, we did not find substantial agreement between the values described in the literature, presenting a high variation of values even when the same technique was used, suggesting there is still a need to better define these morphometric parameters. Furthermore, we noted there is no data that differentiates the characteristics of the MIC in different age groups and sexes, which did not allow a better comparison with our data. Therefore, better comparison with our data was not possible.

As the main limitation of the study, we can mention use of panoramic radiographs rather than a computerized tomography analysis. However, this method of analysis was used in order to access exams from an existing database at the Universidad de La Frontera. For future studies we intend to use the two methods and make comparisons between the measurements obtained.

The data of the present study allows us to conclude that the MIC prevalence in the study population was 53 $\%$, with higher prevalence and diameter in men; and longer in younger people. The digital panoramic radiography shows a better rate of MIC detection. The morphometric data were in agreement with those previously published with regard to the variation range of the measurements, however there is still disagreement with respect to the mean values, this fact shows the need for a greater number of studies on MIC that can help to elucidate, or even eliminate this discordance. 
FUENTES, R.; ARIAS, A.; BUCCHI, C.; SARAVIA, D. \& DIAS, F. Prevalencia y características morfométricas del canal incisivo mandibular a través de radiografías panorámicas en población chilena. Int. J. Morphol., 35(3):931-937, 2017.

RESUMEN: El canal incisivo mandibular (MIC) es una continuación del canal mandibular, anterior al agujero mentoniano, que contiene la rama neurovascular de los dientes en el segmento mandibular anterior. El objetivo de este estudio fue calcular la prevalencia y analizar los parámetros morfométricos del MIC en una población chilena mediante radiografías panorámicas digitales. Se realizó un estudio de corte transversal utilizando 500 radiografías panorámicas digitales de individuos adultos. La prevalencia de MIC se estableció en diferentes géneros, grupos de edades y proximidad a los dientes; Además de los parámetros morfométricos de longitud, ancho (diámetro) y distancias de MIC al diente y a la base mandibular. La prevalencia general de MIC fue de $53 \%$ (265 casos), 49,9\% en mujeres y $57 \%$ en hombres. En los grupos de edad, la prevalencia fue mayor en los hombres, el MIC se asoció predominantemente a los primeros premolares $(98,2 \%$ - mujeres, $90 \%$ - hombres), sin embargo un número relevante (42,6\% mujeres y $55,1 \%$ hombres) estaba cerca de los caninos. La longitud del MIC osciló entre 2,6 y $18 \mathrm{~mm}$ (medianas de 5 a $8 \mathrm{~mm}$ ), el ancho de 0,8 a $5,4 \mathrm{~mm}$ (medianas de 2 a $3 \mathrm{~mm}$ ), la distancia a otros elementos de 0,6 a $12,5 \mathrm{~mm}$ (medianas de 5 a $7 \mathrm{~mm}$ ) y al borde de la mandíbula de 4,1 a 16,7 $\mathrm{mm}$ (medianas de 8 a $10 \mathrm{~mm}$ ). El largo disminuye en los grupos de mayor edad independientemente del sexo. Ancho y distancia a la base mandibular fue mayor en hombres que en mujeres.

PALABRAS CLAVE: Canal incisivo mandibular; Prevalencia; Morfometría; Población chilena.

\section{REFERENCES}

Apostolakis, D. \& Brown, J. E. The dimensions of the mandibular incisive canal and its spatial relationship to various anatomical landmarks of the mandible: a study using cone beam computed tomography. Int. J. Oral. Maxillofac. Implants, 28(1):117-24, 2013.

Beltrán, V.; Cantín, M.; Fuentes, F. R. \& Engelke, W. Bilateral presence of mandibular incisive canal. An anatomical structure with clinical relevance. Int. J. Morphol., 29(2):543-9, 2011.

de Brito, A. C.; Nejaim, Y.; de Freitas, D. Q. \& de Oliveira Santos, C. Panoramic radiographs underestimate extensions of the anterior loop and mandibular incisive canal. Imaging Sci. Dent., 46(3):159-65, 2016.

Fuentes, R.; Bucchi, C.; Navarro, P.; Beltran, V. \& Cantin, M. Characterization of anatomical structures using panoramic X-rays: Part II: Mandibular incisive canal. J. Anat. Soc. India, 64(2):128-32, 2015.

Holm, S. A simple sequentially rejective multiple test procedure. Scand. J. Stat., 6(2):65-70, 1979.

Jacobs, R.; Mraiwa, N.; van Steenberghe, D.; Gijbels, F. \& Quirynen, M. Appearance, location, course, and morphology of the mandibular incisive canal: an assessment on spiral CT scan. Dentomaxillofac. Radiol., 31(5):322-7, 2002.

Jacobs, R.; Mraiwa, N.; van Steenberghe, D.; Sanderink, G. \& Quirynen, M. Appearance of the mandibular incisive canal on panoramic radiographs. Surg. Radiol. Anat., 26(4):329-33, 2004.

Kabak, S. L.; Zhuravleva, N. V.; Melnichenko, Y. M. \& Savrasova, N. A.
Study of the mandibular incisive canal anatomy using cone beam computed tomography. Surg. Radiol. Anat., 39(6):647-55, 2016.

Kong, N.; Hui, M.; Miao, F.; Yuan, H.; Du, Y. \& Chen, N. Mandibular incisive canal in Han Chinese using cone beam computed tomography. Int. J. Oral Maxillofac. Surg., 45(9):1142-6, 2016.

Kajan, Z. \& Salari, A. Presence and course of the mandibular incisive canal and presence of the anterior loop in cone beam computed tomography images of an Iranian population. Oral Radiol., 28(1):55-61, 2012.

Mardinger, O.; Chaushu, G.; Arensburg, B.; Taicher, S. \& Kaffe, I. Anatomic and radiologic course of the mandibular incisive canal. Surg. Radiol. Anat., 22(3-4):157-61, 2000.

Monsour, P. A. \& Dudhia, R. Implant radiography and radiology. Aust. Dent. J., 1:S11-25, 2008.

Mraiwa, N.; Jacobs, R.; Moerman, P.; Lambrichts, I.; van Steenberghe, D. \& Quirynen, M. Presence and course of the incisive canal in the human mandibular interforaminal region: two-dimensional imaging versus anatomical observations. Surg. Radiol. Anat., 25(5-6):416-23, 2003.

Orhan, K.; Icen, M.; Aksoy, S.; Ozan, O. \& Berberoglu, A. Cone-beam CT evaluation of morphology, location, and course of mandibular incisive canal: Considerations for implant treatment. Oral Radiol., 30(1):64-75, 2014.

Pereira-Maciel, P.; Tavares-de-Sousa, E. \& Oliveira-Sales, M. A. The mandibular incisive canal and its anatomical relationships: A cone beam computed tomography study. Med. Oral Patol. Oral Cir. Bucal, 20(6):e723-8, 2015.

Pires, C. A.; Bissada, N. F.; Becker, J. J.; Kanawati, A. \& Landers, M. A. Mandibular incisive canal: cone beam computed tomography. Clin. Implant Dent. Relat. Res., 14(1):67-73, 2012.

Raitz, R.; Shimura, E.; Chilvarquer, I. \& Fenyo-Pereira, M. Assessment of the mandibular incisive canal by panoramic radiograph and cone-beam computed tomography. Int. J. Dent., 2014:187085, 2014.

Ramesh, A. S.; Rijesh, K.; Sharma, A.; Prakash, R.; Kumar, A. \& Karthik. The prevalence of mandibular incisive nerve canal and to evaluate its average location and dimension in Indian population. J. Pharm. Bioallied. Sci., 7(Suppl. 2):S594-6, 2015.

Romanos, G. E.; Papadimitriou, D. E.; Royer, K.; Stefanova-Stephens, N.; Salwan, R.; Malmström, H. \& Caton, J. G. The presence of the mandibular incisive canal: a panoramic radiographic examination. Implant Dent., 21(3):202-6, 2012.

Sahman, H.; Sekerci, A. E.; Sisman, Y. \& Payveren, M. Assessment of the visibility and characteristics of the mandibular incisive canal: cone beam computed tomography versus panoramic radiography. Int. J. Oral Maxillofac. Implants, 29(1):71-8, 2014.

Uchida, Y.; Yamashita, Y.; Goto, M. \& Hanibara, T. Measurement of anterior loop length for the mandibular canal and diameter of the mandibular incisive canal to avoid nerve damage when installing endosseous implants in the interforaminal region. J. Oral Maxillofac. Surg., 65(9):1772-9, 2007.

Vu, D. D.; Brockhoff, H. C. 2nd; Yates, D. M.; Finn, R. \& Phillips, C. Course of the mandibular incisive canal and its impact on harvesting symphysis bone grafts. J. Oral Maxillofac. Surg., 73(2):258.e1-258.e12, 2015.

Xu, Y.; Suo, N.; Tian, X.; Li, F.; Zhong, G.; Liu, X.; Bao, Y.; Song, T. \& Tian, H. Anatomic study on mental canal and incisive nerve canal in interforaminal region in Chinese population. Surg. Radiol. Anat., 37(6):585-9, 2015.

\section{Corresponding Author:}

Dr. Ramón Fuentes

Facultad de Odontología, Universidad de La Frontera

01145 Av. Francisco Salazar

Casilla 54-D

Temuco

CHILE

Received: 02-05-2017

Accepted: 12-06-2017

E-mail: ramon.fuentes@ufrontera.cl 